\title{
Does accredited professional development for academics improve teaching and learning in Higher Education?
}

\author{
Claire McAvinia \\ Technological University Dublin, claire.mcavinia@tudublin.ie \\ Roisin Donnelly \\ Technological University Dublin, roisin.donnelly@tudublin.ie \\ Claire M. McDonnell \\ Technological University Dublin, claire.mcdonnell@tudublin.ie
}

See next page for additional authors

Follow this and additional works at: https://arrow.tudublin.ie/ltcbk

Part of the Higher Education Commons

\section{Recommended Citation \\ McAvinia, C., Donnelly, R., McDonnell, C., Hanratty, O., \& Harvey, J. (2015). Does accredited professional development for academics improve teaching and learning in Higher Education? In M. Filipa, Y.P., Ribeiro, \& B. Culum (Eds.), New Voices in Higher Education Research and Scholarship. Hershey PA : Information Science Reference, 2015}

This Book Chapter is brought to you for free and open access by the Learning Teaching \& Assessment at ARROW@TU Dublin. It has been accepted for inclusion in Books/Book Chapters by an authorized administrator of ARROW@TU Dublin. For more information, please contact arrow.admin@tudublin.ie, aisling.coyne@tudublin.ie,gerard.connolly@tudublin.ie.

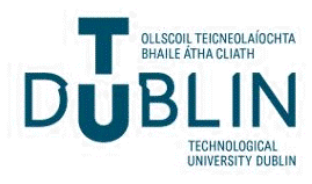




\section{Authors}

Claire McAvinia, Roisin Donnelly, Claire M. McDonnell, Orla Hanratty, and Jen Harvey 


\title{
Does accredited professional development for academics improve teaching and learning in Higher Education?
}

\author{
Claire McAvinia, Roisin Donnelly, Claire McDonnell, Orla Hanratty, Jen Harvey \\ Dublin Institute of Technology, Ireland
}

\begin{abstract}
This Chapter examines the extent to which we can assess whether accredited professional development programmes for academics have improved teaching - and students' learning - in higher education. A review of the literature will be presented, along with new research undertaken in our home institution. The authors are part of a team delivering accredited programmes in teaching at tertiary level, and have collaborated to examine the impact of their work and that of the team over more than ten years in this area. Our findings from both the literature and our most recent research within our own institution indicate a range of benefits for higher education in providing and supporting accredited programmes for educators. However, we have also identified methodological issues in measuring these benefits and impact overall. The Chapter will discuss this work and connect it with the broader themes of this book. We emphasise the importance of effective teaching in the midst of the many complex changes influencing higher education at this time.
\end{abstract}

\section{INTRODUCTION AND OBJECTIVES}

Since the early 1990s, academic professional development has emerged as a formal activity in most third level institutions in the UK, Ireland, Australasia and the US (Gosling, 2009). This trend led to the inception of centres for academic development, including the Learning, Teaching and Technology Centre (LTTC) at Dublin Institute of Technology (DIT) in Ireland. Since 2000, the LTTC has provided accredited academic development programmes and short courses for academics within and externally to the Institute. DIT spans a number of sites in Dublin city, with some 20,000 students from apprentice to doctoral levels. Disciplines are organized into four Colleges: Arts and Tourism, Business, Engineering and the Built Environment, and Sciences and Health. Given the range of staff attending, the longevity of our programmes, and the many challenges now facing higher education, we sought to re-examine our provision and to evaluate the impact of accredited courses over some years.

The value of teaching as a professional area of activity in higher education has only relatively recently been identified and studied (Hanbury, Prosser \& Rickinson, 2008; Kandlbinder \& Peseta, 2009). The past two decades have seen concerted efforts made to develop teaching as a formal professional activity in higher education in many parts of the world (Fink, 2013; Kandlbinder \& Peseta, 2009). A strong trend for professional development programmes has emerged, particularly for new staff, and many universities have developed postgraduate qualifications in higher education (Chalmers \& Thompson, 2008). Critical reflection on practice in higher education has emerged as potentially an important means to develop teaching practice (Bamber \& Anderson, 2012; O'Connell \& Dyment, 2006). 
Funded initiatives have also foregrounded teaching enhancement. In Ireland and the UK, funding has been connected directly with the creation and implementation of institutional learning and teaching strategies (for example, the Teaching Quality Enhancement Funds in the UK (2000-2004) and Strategic Innovation Funds in Ireland (2006-2011)). National forums and academies for teaching and learning have emerged (http://www.heacademy.ac.uk; http://www.teachingandlearning.ie/), defining priority themes for academic professional development and the enhancement of students' learning.

Academic development units and services began to challenge the predominance of traditional teaching methods, taking more constructivist approaches in their workshops and courses (Bostock, 1998; Laurillard, 2001; Entwistle, 2009; Jordan, et al., 2008), gaining funding as well as senior level support for their efforts. Innovation and change in teaching and learning were articulated in a manner that was appropriate to institutions and to their lecturers through the development and launch of accredited programmes (Kandlbinder \& Peseta, 2009).

In light of this history, our objectives in this Chapter are twofold. First, we examine in detail emergence of accredited teaching courses at tertiary level, and where these may fit in the evolving landscape of higher education nationally and internationally. Second, we consider the evidence in relation to this kind of professional development, and whether it can be said to have improved teaching and learning. We draw both on the literature, and on a local evaluation of accredited courses at DIT. We will identify the learning points from this work, and the future directions in which research could be taken.

\section{CONTEXT AND LITERATURE REVIEW}

A review of the literature related to our research objectives indicated three over-arching themes for discussion:

- The development of teaching as a formal, professional activity in higher education;

- The evolving national and international contexts for this work;

- The potential impact of accredited programmes and measuring this impact.

Each of these will be addressed in this section.

\section{Professionalising teaching in higher education}

For approximately 20 years, programmes of continuing professional development have been established in universities and other tertiary institutions in Europe, the US and Australasia. Fink (2013) identifies four levels of growth internationally, ranging from limited or no activity (for example, in Africa and parts of Asia and Europe) to well-embedded systems of continuing professional development by all faculty (Sweden). Ireland is not mentioned in Fink's survey, but could arguably be placed at Level 3 of this framework, in that there is activity in academic development at nearly all higher education institutions, with some obligatory participation in workshops. In the case of the DIT, there is mandatory participation in the Postgraduate Diploma in Third Level Learning and Teaching for newly appointed lecturers since 2006.

In common with the UK, Ireland has seen a trend from the late 1990s onwards towards the gradual provision of formal academic development opportunities and ultimately accredited courses. The Staff and Educational Development Association (SEDA) in the UK launched an initiative to accredit teachers in higher education in 1990, with a pilot at eight institutions. Following the publication of the Dearing Report (NCIHE, 1997), and the recommendation that staff should undertake formal courses in teaching and learning, these programmes began to grow. Some 168 Higher Education Academy accredited courses existed in 2007 (Kandlbinder \& Peseta, 2009, p. 20), and the Academy aligns courses and other forms of professional development to its Professional Standards Framework (http://www.heacademy.ac.uk/ukpsf). In Ireland, there is a smaller sector of 21 publicly-funded higher education institutions. Academics have a range of qualifications to choose from, some leading to further study at Masters and doctoral level. In addition, standalone accredited modules have been developed and delivered collaboratively by the Learning Innovation Network (www.lin.ie) and Dublin Region Higher Education Alliance (www.drhea.ie.). 
Researchers have asked why such activities have grown in the past number of decades, and suggest a number of reasons: that growing evidence pointed to the limitations of "traditional" modes of teaching, that training was previously piecemeal, that students were only achieving some of the attributes they should at third level, that student retention figures have become a cause for keen concern in many countries, and that new technologies offer a further and very significant challenge (Fink, 2013; Lueddeke, 2003). Governments expect higher education to meet these challenges. Gibbs and Coffey (2004), researching the experiences of staff and students in 20 universities across eight countries found that where teachers participated in academic development programmes, their focus became more student-centred, and lecturers' feelings of self-efficacy and confidence grew. Students in turn adopted strategies for deep learning and reported that their learning experiences were better. Similar findings have been reported more recently by a study in Durham College, Ontario (Rodgers, Christie \& Wideman, 2014). The purpose of professionalizing activities of various kinds is ultimately to enhance student learning but more importantly, to prevent students from leaving (Lueddeke, 2003). Fink (2013) defines academic development in terms of an individual's immediate goals, longer term aims, and ultimately the wider benefit to education and society. The formal development of teaching is argued to feed into these goals, but challenges remain in finding the most appropriate ways of doing this. Lueddeke (2003) suggests that we need to theorise further on the kinds of professional development academics undertake, given that academics' own preference is often to learn professionally through social networks, keep close to their 'home' disciplines, and that any professional development they undertake is subject to the pressures of time and workload. These are significant challenges indeed, and nowhere moreso than in the case of the 'silent majority': those who do not engage with academic professional development. Lueddeke (ibid) found that early and late career academics were most likely to participate, as well as those who had already pursued higher studies in their own careers.

Notwithstanding the challenges of designing appropriate forms of professional development, the value of pedagogic knowledge and learning design has risen dramatically within Irish HEIs over the last few years, with rewards for the development of good practice in these areas now becoming instituted. In the UK, delivery has emphasised institutionally led strategies and provision (accredited or not). Parsons et al. (2012) report that for new and aspiring academic staff, the qualification pathway is becoming a more established feature of institutional strategies. The next section will examine these national and international trends in more depth.

\section{Evolving international and national context}

Higher education (HE) in Ireland and internationally is part of a dynamic and shifting landscape, challenged by the global economic recession since 2008, and by technological change. These factors are important of themselves, but also affect our interactions with our stakeholders, how we react, and how we might influence change as it happens. The increasing profile of teaching in higher education since the 1990s, and its gradual steps towards becoming a more formally recognized activity, now take place against the backdrop of radical shifts in how people access knowledge and information, and what they may expect to gain from any professional qualification.

Generally HEIs are not well known for responding quickly, but the unregulated world of MOOCs, open sharing, relentless innovation, co-curricular development, and moves towards greater crossorganisational collaboration, have come to the fore of conversations and agendas for change. In the Irish context, the high magnitude changes that have taken place in the economy and in society since 2007 require academic developers to reflect and re-examine professional programmes in teaching and learning (along with other disciplines) (Donnelly, 2008).

There has been ongoing discussion in the Irish HE system about a proposed reconfiguration of the number of HEIs and their geographical distribution due to what has been called "laissez-faire development" (HEA 2012, p.5), leading to duplication of effort and blurred missions in some areas. 
Ireland's National Strategy for Higher Education to 2030 (DES, 2011) is framed against a range of new challenges facing higher education; it has argued that:

Irish higher education itself will need to innovate and develop if it is to provide flexible opportunities for larger and more diverse student cohorts. It will need to do this while simultaneously enhancing quality and relevance, and connecting better with the wider needs of society and the economy, while operating in a more competitive globalised environment (2011, p.32).

To address this, the newly formed National Forum for the Enhancement of Teaching and Learning in Higher Education (http://www.teachingandlearning.ie/) has identified four priority enhancement themes: supporting teachers in helping students make effective transitions; setting up a national learning impact award system; benchmarking a professional development framework; and building digital capacity. With this focus on recognition of and reward for teaching, maximizing digital learning opportunities, and the introduction of a professional development framework for academics, the National Forum has the potential to be a powerful driver of change in Irish higher education. Existing accredited provision for academic professional development may well have a renewed emphasis in this context.

\section{The impact of professional development programmes}

In light of the established trend towards accrediting professional development in teaching and learning, and the likelihood that this will grow in importance over the next number of years, it is important to examine evidence in the literature as to whether professional development programmes have had the positive impact desired. Studies have investigated whether this kind of professional development has had the effect of improving teaching and learning, and what might be learned from various approaches to this work. It is important to acknowledge that there is still relatively little research evaluating the impact of programmes, and limited evidence to link participation in teaching development programmes with enhanced student learning (Bamber, 2008; Bamber \& Trowler, 2005; Gibbs \& Coffey, 2004; Porritt, 2014). In 2006, Pickering concluded that investigating the impact of these programmes on the practices and beliefs held by academics is not simple or even feasible. We will focus in this section on the work that has been undertaken by (amongst others) Prosser et al. (2006); Rust (2000, 2006); Kahn et al. (2006); Knight et al. (2006); Stes et al. (2007); Hanbury et al. (2008); Trigwell et al. (2012) and Bamber (2013a). We consider also the limitations of this research, and the calls for more robust methodologies to be developed.

Hanbury et al. (2008) researched with programme completers from 32 UK higher education institutions, as well as programme leaders, heads of department and pro-vice-chancellors, and set out to explore the perceived impact of UK-accredited teaching development programmes upon participants and departments. Findings centred on perceptions of impact, with participants perceiving themselves to be significantly more student-focused in their teaching after attending a programme, with those from newer institutions and health sciences disciplines experiencing the greatest conceptual change and rating the programmes most positively. There were some positive examples of departmental impacts, and the programmes were seen to align more closely with institutional teaching and learning strategies than mission statements.

A review by Kahn et al. (2006) for the HEA in the UK, on the use of reflective practice in postgraduate programmes for academic staff emphasised that such programmes are intended to create meaning around practice. Accomplishing this is an inherently collaborative and social process that can lead to changes in practice, capacity for change and changes in professional identity. The evaluative study by Prosser et al. (2006) found that such programmes encouraged the academic staff participating to be more student focused and to help form linkages between departments. The conclusion of the study by Knight et al. (2006) on the effectiveness of postgraduate certificates in the field, was that there were varying levels of satisfaction for teacher development as an outcome of these programmes. 
It may also be challenging to find sufficient time to evaluate, to recognise that professional practice is complex, and to reconcile evaluation processes with the potential to influence management beliefs (Bamber, 2013a). The challenge we face as academic developers is how we can establish shared understandings with those who will assess our value. Bamber (2013a) emphasizes the importance of professional judgment in complex, multi-factoral situations and the recognition of the value of experience, and knowledge of the context, intelligently used. Ultimately it is key for us to remember that academic development (and its programmes), has long, slow-burning effects.

Reviewing the literature which addresses the impact of accredited teaching development programmes points to positive effects, albeit with some tentative conclusions and a growing awareness of the complexity of teachers' own conceptions of teaching and learning in the context of an increasingly busy workload. Carrying these findings forward, we sought to design an appropriate evaluation of our own accredited programmes.

\section{MEASURING IMPACT: A CASE STUDY}

\section{Context}

The previous review and discussion of the literature has shown that although there has been formal development of teaching as a professional activity in higher education, and this has been articulated through accredited programmes, there are important challenges in tracing the impact of this work. Methodological challenges exist, and researchers are still working to build an evidence base in this area.

In seeking to assess the impact of our own courses, we engaged first with the evaluation literature. Stake (2004) has suggested that evaluation is the discernment of the good in our work. Baume (2008) indicated three purposes for such evaluation - to account, to improve, to understand. He argues that we should look at the setting, the people, the atmosphere, the environment as well as what is happening and why. It is good practice to think about evaluation being collaborative, and indeed how evaluation fits with the key elements of the change lifecycle: preparing, planning, implementing, and sustaining change to practice. Fleming (2012) believes that in order to add value to the evaluation of complex change, evaluation questions need to energise rather than stifle innovation, and it is important to keep the thinking about any initiative nuanced, flexible, responsive and rigorous. It is useful to consider the use of 'double loop learning' - what did and did not work and use the findings to facilitate innovative thinking about the initiative as it progresses. These varying models for evaluation point to the complexity of the task, and perhaps explain in some measure the methodological difficulties facing academic developers in the evaluation of the impact of their work. But they also indicated the need for deep, rich descriptions of experience and the potential of qualitative research methods, rather than attempting a positivist study to measure impact (Cohen, Manion \& Morrison, 2011).

Bamber (2013b) suggests a useful eight step framework for evidencing the value of our academic development work: explore the evaluation literature; elucidate our theory of change; plan the evaluation; choose an evidence mix; adopt a systematic approach; remember the role of judgment and subjectivity; bring in evidence-based cases; and contribute to the literature. We have followed this model to support the design of this evaluative study:

- We consulted the evaluation literature and the existing research available.

- We theorised that 'change' in the context of academic professional development would likely be evidenced by changes in teaching practice towards more student-centred learning, and away from transmission-oriented approaches to teaching.

- We planned and undertook an evaluation project to examine the impact of our three accredited programmes: the Postgraduate Diploma in Third Level Learning and Teaching (previously known as the Postgraduate Certificate in Third Level Learning and Teaching), as an accredited course which has been in place since 2000 and completion of which is a requirement since 2006 
for members of staff new to teaching at DIT; the MA in Higher Education (in place since 2000) and the MSc in Applied eLearning (established in 2006).

- Our chosen methods determined the evidence mix: a questionnaire to internal and external alumni of the accredited programmes and short courses; focus groups with members of staff at the Institute who had completed accredited programmes or short courses.

- A systematic approach to the study was adopted and is reported in the Implementation section below.

- Our own roles as course co-ordinators and tutors were consciously recognised throughout the process. This was especially important in addressing the ethical issues associated with the research. The authors work with graduates of our programmes as colleagues in DIT and at the external institutes. Many of our DIT colleagues return to our Centre to participate in other courses, or as members of working groups and committees. It was appropriate to use the Institute's procedures for ethical approval of the research, and following submission of our project proposals and data collection instruments, approval was granted. The questionnaire was distributed by a colleague in our administrative office, to remove the authors one degree from the data collection. The focus groups were facilitated by the colleague newest to the team, who had not previously met the programme alumni.

- Evidence-based cases: the longevity of our courses, which were established in the 2000s, indicated a large group of alumni from whom data could be collected. We gathered data from those both internal and external to the Institute, who were engaged in teaching in other higher education institutions in Ireland or in a teaching/training role within their organisations. We asked whether accredited training and professional development for academics had led to changes in their teaching, whether these changes had been positive, and whether the student learning experience had been enhanced.

- We seek here to make a contribution to the literature, deriving from this work. In addition, the research has been presented at two conferences (Harvey, Donnelly \& McAvinia, 2013; McAvinia et al., 2014) and reported through formal channels at the local level.

\section{Implementation}

227 internal and external alumni of our courses were contacted via email to invite their participation. 78 of them returned questionnaires, representing a response rate of $34 \%$. The questionnaires were administered using an online survey system.

Frequency data was provided in a range of charts by the online system. This system also allowed us to compare the quantitative results across the two surveys. Most of the respondents were working in Institutes of Technology $\mathrm{y}^{\mathrm{i}}$, and there was some distribution of responses across the disciplines. A higher proportion of the internal respondents were at an earlier point in their teaching careers, teaching for less than five years. This may reflect the requirement since 2006 for newly appointed DIT teaching staff to take the Diploma course within their first two years of employment. For the external group, length of time teaching was more varied.

Graduates of the Certificate/Diploma and Masters courses, and also the accredited short courses, from 2008-2013 were contacted and invited to attend a focus group. Eight participants attended as two separate groups. Notwithstanding the small sizes of these groups, three of the four Colleges of the Institute were represented, and each participant came from a separate department or school within his/her College. As participation was on a voluntary basis, we could not guarantee attendance from all four Colleges and unfortunately one College was not represented. The focus groups were recorded and fully transcribed, with a thematic analysis of the data undertaken (Bryman \& Burgess, 1994).

\section{Limitations of the Research Design}

It is important to acknowledge the limitations of the research design adopted, notwithstanding the eight-step approach we have taken informed by the work of Bamber (2013b) in researching academic development. Even with an awareness of the limitations of similar studies (Literature Review), we 
could not necessarily design these out of the evaluation reported here. An interpretivist approach drawing on qualitative methods is appropriate to our stance as researchers, but for ethical reasons participants were self-selecting, and data is self-reported. The data reflect the participants' perceptions of the impact of the accredited programmes on their students' learning, but we do not have data from the students themselves. Even with such data it would be difficult to identify where and how (precisely) student learning had been enhanced, but we make some recommendations to address this point later in the Chapter.

\section{Findings}

\section{Questionnaire}

This section presents summary findings from the closed questions on the questionnaire, to provide context for the analysis of qualitative data which follows in the subsequent section. The data showed that alumni had a high degree of satisfaction with their chosen courses, they reported benefits for their departments and for their students, and many had continued studying.

93\% of the questionnaire respondents said their expectations had been met by their course, with $96 \%$ saying their teaching practice had changed. $92 \%$ said they had seen changes in their students' learning as a result of their changed practices. $82 \%$ of the respondents reported benefits for their departments as a result of their having taken the course, particularly around development of teaching, and also their skills in taking on course redesign and development. Nearly $80 \%$ of respondents said they could identify an underlying ethos to the programmes, most identifying the student-centred focus of LTTC courses, which was encouraging as our team has sought to instil a student-centred approach to our work.

The vast majority of respondents did not have a teaching qualification before undertaking their chosen programme. Overall, five people had completed short courses, 54 had completed the

Certificate/Diploma, 23 had completed the MA in Higher Education and 10 had completed the MSc in Applied eLearning. Some people had completed more than one course at the LTTC, and for both internal and external groups there was evidence of progression from the Certificate/Diploma to either the MA or MSc. 25\% were continuing their studies at doctoral level, but DIT staff were overrepresented in this group: external staff were less likely to be undertaking doctoral level studies.

\section{Analysis of Qualitative Data}

This section presents analysis of the qualitative data obtained in the questionnaire and the two Focus Groups. Data were analysed thematically (Bryman \& Burgess, 1994). We present first the findings in respect of the identified themes, in order of importance. These findings will be discussed in relation to the research objectives in Solutions and Recommendations.

\section{Colleagues in collaborative learning}

The most important theme to emerge from the focus group discussions, and which emerged repeatedly in response to a range of questions, was the benefit of working as part of a class cohort and interacting with colleagues during an accredited course.

Certainly being able to meet people from such a broad range of disciplines, to be put into that kind of mix, to see how the Engineers think, to see how the Chemistry people think, from [named College] for example, it was very, very stimulating (Participant 3, Focus Group 1)

These interactions were separate to the collegial relationships participants had in their own teams or disciplines, and were characterised as being beneficial precisely because of the differences, and because of the opportunities to meet people from other institutions or subject areas. While it might be argued that such networks could be fostered independently of accredited programmes, participants commented on the value of their courses as a safe space to discuss their teaching. The potential to confer with colleagues on new approaches to teaching, new methods, tools and techniques, was of crucial importance and could not be replaced by reading or accessing the information in other ways. 
The fact that you are meeting like-minded people, like-minded people in the same place, and that's really the big thing for me, you know that you're put in with a group of people who are talking about things, and if you get people talking about things, then you get to improve them and start thinking about things in a different way yourself. So that was the key benefit for me. (Participant 1, Focus Group 1)

More formal - and formative - collaborations were undertaken through groupwork, which was identified as a key benefit of participation in an accredited course. However, this was also a significant challenge for some people, and their experiences informed their own use of groupwork in their classrooms. Once they had become accustomed to group work, it became a valuable learning experience. Following completion of the Certificate/Diploma, in particular, there was a sense of belonging to a network or even a group of alumni, and the social dimension of being in that group persisted, providing additional support to participants:

When you talk to people, (..) when you do the Cert or Diploma or whatever, and the next question usually is, who was on it when you did it? [laughter] Because we all knew each other to a certain extent, and there's a huge benefit and support in that. (Participant 2, Focus Group 1)

Developing confidence in teaching

The second theme to emerge consistently throughout the focus group discussions was that of confidence. For many of the participants, there was no difficulty in thinking about introducing changes to their teaching, but initial reluctance or a fear that something could go wrong. There were repeated references to the development of confidence in teaching, confidence in making changes to programmes, and in the introduction of new methods for assessment or feedback:

You could still try new things but it's easier and you have more confidence because of learning about it first and - crucially - having had the chance to discuss it with other people in the class (Participant 2, Focus Group 1)

While other settings could afford the development of confidence in teaching, the accredited courses provided authentic exercises in making significant change (for example, introducing problem-based learning, or redesigning modules) before making these changes in reality. There was a keen awareness that lecturers could not just experiment in class - they had to be mindful of their students' needs too:

it would be very difficult to attempt something like that without having been here [in the course]. You could probably do it but you would probably have casualties along the way, which are people's future, and you can't mess with people's future (Participant 2, Focus Group 1)

Enhancing students' learning

Participants reported numerous examples of how their accredited courses had positively impacted on their teaching and their students' learning. For some, these experiences had been transformational in nature:

Well, I mean when I first started I could see that the lecturing thing wasn't really very, a very positive experience for all involved, so by attending the course here and by talking to others outside I was sort of able to transform practice, so it has totally changed (Participant 1, Focus Group 2)

They responded keenly to the question of whether students' learning had improved as a result of their own participation in accredited courses in teaching and learning:

I would have to say absolutely (..) I would have to say there's been a transformation in the way that students have engaged.

Positive learning experiences affected their students' confidence too: 
you can see that they're more confident, and when they're going into project work as well they're much more confident and self-assured, and like that's fantastic (Participant 5, Focus Group 2)

We have previously stated some of the limitations of this research inasmuch as participants were drawn from programme alumni, and measuring the impact of accredited programmes from the perspective of students was not practicable in this particular study. However, participants did comment on factors supporting their observations of change in discussing student engagement and retention. For example, Participant 4 (Focus Group 2) describes a change in attendance rate following the introduction of active learning methodologies in his teaching:

And you know that's very easily measurable I guess in the way that they will attend modules because if, you know, if it's not working out the way they expect, or if it's not exceeding their expectations, they'll drift away quickly, and in some very difficult modules that don't sound at all sexy, the attendance rates have rocketed and students are fully engaged, and producing extraordinary work.(Participant 4, Focus Group 2)

The discussion also focused on sustaining changes in teaching which could lead to greater levels of student engagement. Change in one topic or module led to thinking more about how and where it fitted with the full programme. The challenge then was to continue to innovate, and to try to redesign the curriculum rather than just isolated pockets of activity within it, and this was linked with the expectations of students:

you start to realise that and you start to think well if there was more of this in the programme, they might be more prepared for these modules then when they get to them. So I've been sort of trying to chip away on the curriculum level with others and to try and sort of not just reform my teaching practice but to try and help reform the curriculum (Participant 1, Focus Group 2)

But the focus group participants, were also very clear about the challenges they had encountered. Introducing different methods of learning and teaching brought its own difficulties, and again the place of student-centred modules in a broader curriculum could be difficult to reconcile:

student-centred learning isn't necessarily student-friendly. Student-centred learning can be quite hard on students, it's much more, independent thinkers and so on, and if they're just getting little islands of it in the curriculum I don't know (..) if the entire curriculum had a student-centred learning approach it should be more effective (Participant 1, Focus Group 2)

These examples show that graduates of the accredited courses changed their own teaching methods and practices, had seen increased levels of student engagement, and had begun to look at sustaining change in the wider curriculum. The feedback indicating that student motivation is raised, that retention in class has improved, and that the quality of students' work has been significantly enhanced, suggests a range of positive outcomes from their experiences of accredited professional development.

\section{Learning the language}

Engaging with the scholarship of teaching and learning had contributed to the confidence people had in their work, as well as giving them a new area in which to research and publish. They felt they had the language and terminology to engage with teaching and learning issues, and research. Participants described significant personal benefits and a sense of achievement as they had published their work, and spoken at conferences about their pedagogical research. Participant 3 in Focus Group 2 described three separate publications derived from the MA, and an invitation to present at an upcoming conference:

I would never have thought four years ago that I would ever have been doing anything like that or have the confidence to do something like that and I think doing the MA and having to write a 
conference paper and having to present it you know even just here in front of your peers (..) that really enabled me, and I think the peers that were on the course at the time to be able to do things like that (Participant 3, Focus Group 2)

Having acquired the 'language' of teaching and learning, participants were also better equipped to deal with institutional programme documentation, validation processes and other issues (Participant 2, Focus Group 1). Their studies had enabled them not only to manage course administration, but also to develop and validate new courses and to respond to the changing economic climate which called for programme modernisation (Participants 2 and 3, Focus Group 1).

\section{Positive impact on home Department/School}

There was frequent discussion in the focus groups of the broader impact their experiences had had back in their Schools and Departments. Different threads could be identified here: participants had been successful in winning institutional project funding (Participants 1 and 2, Focus Group 1; Participants 1, 2 and 3, Focus Group 2). They were able to share their knowledge and experiences with colleagues, and contribute to innovations:

you can see the benefit across, as a School, it's been useful and I know we've shared a lot of information as well within the College not just within the School (..) we've revamped a lot of programmes and modules, in terms of how you assess, and just aligning all our learning outcomes with our assessment and looking at the big picture (Participant 5, Focus Group 2)

In a few cases, the work undertaken with colleagues in a School or Department had led into the establishment of semi-formal groups. These groups were focused on issues in teaching or "educational research" (Participant 5, Focus Group 2). They examined the development of teaching and learning in the discipline, and often coordinated efforts to obtain funding, try new methods or to look at on-going professional development opportunities together. These examples point to the potential longer-term added value of the accredited courses, and additional return for Departments and Schools investing in continuing professional development for their staff.

\section{Practical issues and challenges}

In both the questionnaire and the focus group strands of this research, we sought to hear from participants in detail about the practical issues and challenges associated with attending an accredited programme. The investment of time in an accredited course (from both individual and home department) is significant, and although positive outcomes had been reported these needed to be balanced against the practical difficulties and challenges encountered. These will be summarised here in the interests of space, but have been reported them in greater detail locally.

Internal and external respondents to the questionnaire were motivated to enrol in programmes because they were interested in the topics, wanted a teaching qualification or wanted to experience new teaching methods from a student's perspective. Practical arrangements around the courses did not seem to influence the decision to enrol, although time pressures once studying were considerable. Obtaining permission to be away from teaching in order to study was difficult, and was referred to by all participants in the Focus Groups. Their studies were often accommodated only in their spare time:

I would have done a lot of the assignments in, at Christmas, Easter, whenever you had a break, and just fly through them, which was, all of your holidays was used to do your assignments, because like you have 20 hours teaching, and that's just teaching, then there's correcting and so on, so it's at the worst stage of your career but it is when you need it most (Participant 5, Focus Group 2)

Participants in both Focus Groups felt that it was essential for new lecturers to have a teaching qualification. Without professional development, it was felt that new lecturers would naturally teach in the way they had been taught themselves: 
..very easy to get into a rut where you say, this is how I teach, you give your notes and you walk away again, particularly if you're given a lot of hours at the start and once you get into that sort of situation you might just say that's the way it is and never move on (Participant 1, Focus Group 1)

In spite of the time challenges, the practical arrangements for the courses were not considered to be obstacles. In terms of the content of the accredited courses, some participants felt that some modules might be too theoretical, and that there might be greater use of new technologies and social media. But they also recalled having enjoyed modules when they had not expected to (Participant 3, Focus Group 1), and argued against changing challenging activities such as micro-teaching and teaching observation. There is also evidence from some of the examples discussed at the focus groups (and in the questionnaires) of a greater engagement with e-learning, including the institutional virtual learning environment, audience response systems, and podcasting/screencasting following completion of an accredited course.

Alternative forms of accreditation were discussed, such as more flexible modular structures for courses or independent completion of a teaching portfolio. However, although there had been positive responses to this in the questionnaires, there was much more caution amongst the focus group participants. It was felt that more flexible forms of accreditation could encourage people to work strategically, rather than participate and engage fully with course materials and activities. Once again, the importance of learning with colleagues and interacting with them emerged from this discussion:

the course isn't really content-driven, it's not really you have to attend these classes and you have to read the notes and you have to... it's I think what you learn is by attending and actually communicating with the other people on the course and I think for a lot of postgraduate courses even within your discipline that would be the same, it's not really what you're reading, it's a sharing of different perspectives and how things work (Participant 5, Focus Group 2)

\section{The wider importance of learning and teaching in an institution}

We asked participants about whether and how teaching was valued within their home departments and organisations. This issue relates to the broader discourse on the importance of qualifications in teaching at third level, and the status of teaching in higher education (discussed in the opening sections of this Chapter). Aside from their informal working groups, and keeping in contact with fellow alumni, participants were not sure of the broader importance attributed to teaching development. Their work, including their educational research, might not be recognized as readily as disciplinary research. Research metrics did not include educational research and it was not counted (Participant 5, Focus Group 2). However, when other metrics for quality assurance in teaching were being applied, the work then became valued.

Re-designed courses using active learning methods were often regarded as being more resourceintensive than those taught through lectures, making them a hard sell to colleagues. Notwithstanding institutional support for the development of teaching, it could be difficult for individuals to implement the kinds of changes they felt programmes and modules then needed. In one case, a participant felt his department was making a more conscious effort to recognise the work of staff in gaining qualifications in teaching and the innovations they were making to curricula. This may have been related to the requirements of their allied professional body, but nonetheless he felt that "at least it's there, and the moment is there" (Participant 1, Focus Group 2). This perhaps indicates the importance of certain external drivers, including professional bodies' accreditation processes, in supporting academic development in higher education.

The focus group participants appeared to agree that it would take time, and also a 'critical mass' of qualified and/or interested colleagues before recognition of the importance of teaching would be achieved across an organisation. Even then, however, it would be unlikely to help with an individual's chances of promotion. 


\section{Discussion}

In this Chapter, we have asked whether accredited training and professional development for academics has led to changes in their teaching, whether these changes have been positive, and whether the student learning experience has been enhanced. We adopted an interpretivist stance for this research, using qualitative methods and framing the work in the evaluation model proposed by Bamber (2013b). We sought to address the experiences of more than 200 alumni of our accredited professional development programmes through a systematic approach to the study, and conscious recognition of our own roles in the research process.

Our review of the literature indicated mixed findings from the work of other researchers, but also identified the theoretical and methodological difficulties inherent in gathering evidence in relation to the impact of programmes. We experienced similar challenges in our own work. In particular, the issue of measuring impact from the perspective of students themselves is unresolved, and results in research reliant on the reports of those doing the teaching. This may be mitigated through the evidence mix: the strength of the data from our closed questionnaire questions validates the detailed reported experiences of the participants in our focus groups. However, other approaches to this issue could include the analysis of examination results, student retention and progression rates, and qualitative data-gathering with the students themselves - provided an ethically sound design could be made for this.

The results of our research indicate that academics have changed their teaching as a result of undertaking accredited professional development, and that they feel their students have benefited as a result. Participants saw many positive changes in students' learning, and were able to give numerous examples from their practice. Students were engaged with their courses, retention within courses had been improved, and students' work was of a higher quality. The personal and professional benefits to participants were also clearly evident, with many participants continuing their studies and moving into both educational research and research in their disciplines. These benefits should not be seen only in terms of one individual's continuing professional development, but also in terms of the relationship between teaching and research, with teaching leading into research and into new fields of research for some. Participants were reporting longer term impacts as they may have completed the programme a number of years previously and therefore had time to develop and change their practice. Taken together, these findings indicate the value of accredited development for the enhancement of teaching and learning, even if as researchers we face a range of challenges in measuring this value accurately.

These benefits have emerged notwithstanding the struggles and challenges both academics and students face in undertaking their studies. Institutional strategies prioritise excellence in disciplinary research, and resource constraints may well favour traditional modes of transmission-oriented teaching. While there is greater recognition emerging at national level for academic development, this exists in the context of both government proposals to reconfigure the tertiary sector, and the continuing funding challenges facing higher education.

It is important to acknowledge again the limitations of the research presented here, as a short study conducted on the basis of self-selection by participants. One recommendation emerging from this work is that researchers should expand the methods used to evaluate the impact of accredited programmes over a longer period of time, drawing on the evaluation models discussed earlier in order to build up a clearer picture of impact (Bamber, 2013a, 2013b; Fleming, 2012). If the impact of accredited programmes on classroom teaching and learning is difficult to measure, estimating the impact of such programmes on the institution and on a national higher education sector is an even greater challenge. However, the indications from our work suggest that accredited programmes have an impact far beyond the immediate loci of participants' teaching and that this is worthy of further exploration. Through the work of the programme alumni, curricular change and constructive alignment (Biggs, 2003) are being addressed in schools and departments. Institutions therefore have the opportunity to make substantial progress towards their strategic objectives of excellence in teaching and learning. Course development and validation processes are engaged with in-depth, rather 
than being regarded at a superficial level. Research activity is being developed and enhanced. These developments occur organically as the undefined longer-term learning outcomes of accredited programmes such as ours. The high level of satisfaction amongst external participants demonstrates the appeal of the accredited courses to people outside the 'provider' Institute. Their involvement is highly valued by internal participants for the enriched discussion in class. The sector as a whole is enriched through sharing continuing professional development activities. Furthermore, the appeal of these courses to external participants is also something that can be valued in terms of income generation for the Institute going into the future

There were few indications from this study that participants and graduates of our programmes would suggest major change or restructuring of those programmes, and they have helped to discern the good in our work (Stake, 2004). However, we can identify recommendations for the future too. Impact needs to be researched through more methodologically eclectic designs, and across external contexts as well as the immediate contexts of our programmes. It may be appropriate to increase provision in certain areas, notably in short courses which could build towards particular qualifications. This structure, in tandem with the existing provision, would offer some additional flexibility to staff and perhaps accommodate them more easily given the increasing pressures on their time.

\section{FUTURE RESEARCH DIRECTIONS}

Our review of literature, and the case study presented in this Chapter, have sought to examine the impact of accredited academic professional development programmes in higher education. Evidence has been presented to support the conclusion that such programmes are valuable, and are having a positive impact on teaching and learning. However, this evidence has also demonstrated the complexity and difficulty of developing appropriate research methods to evaluate and measure impact in this area. Future research should address this issue in the first instance, before seeking further evidence from stakeholders and course participants

Stefani (2003) has alluded to the need to become more businesslike in our thinking and approach to evaluation of practice. It is challenging to move in this direction as we know well that HEIs have different purposes to for-profit organisations. They have different ambitions, goals and needs. Whatever metrics we ultimately develop to evaluate the effectiveness of our professional development programmes and initiatives, they will be different to those in business. But they could nonetheless demonstrate cost benefits, for example through student retention and progression. There is a clear sense of the importance of integrating professional development with efforts to improve strategic implementation in our institutions. Our programmes can be evaluated to tabulate their benefits more precisely. In turn, our evaluation should provide better and organisation-specific indicators of what types of development are appropriate, and which should be strengthened, changed or even abandoned.

Other studies have drawn on national surveys of student engagement to compare data with that reported by programme alumni. This could become possible in Ireland with the introduction of a national survey in 2013. Instruments such as the Approaches to Teaching Inventory have also been used to triangulate data in at least one study (Lueddeke, 2003). We propose that this area of work should be the focus of future research efforts in the short term.

\section{CONCLUSION}

In this Chapter, we asked whether accredited training and professional development for academics has led to real changes in their teaching, whether these changes have been positive, and whether the student learning experience has been enhanced. There is emergent evidence in the literature of the effectiveness of accredited programmes, and this is supported by our findings most recently at DIT.

We asked in turn, if it could be possible through the enhancement of teaching and learning, to create a more responsive higher education sector, and whether staff could better address their roles in context through reflective practice. This question is much more difficult to address, and perhaps it should be redefined at the more granular level of changes to lessons, modules and programmes. If we consider 
change at this level, then there is evidence pointing to positive changes in methods, teaching and assessment practices, and the engagement of students in their learning. As these changes become embedded and grow, we may come to see a more responsive sector, contributing more readily to society and better able to meet fresh challenges in a more complex world. 


\section{REFERENCES}

Bamber, V. \& Anderson, S. (2012) Evaluating learning and teaching: institutional needs and individual practices. International Journal for Academic Development. 17 (1), 5-18

Bamber, V. (2008). Evaluating lecturer development programmes: received wisdom or selfknowledge? International Journal for Academic Development, 13(2), 107-116.

Bamber, V. (2013a). Evidence, chimera and belief. SEDA Special, 34.

Bamber, V. (2013b). A desideratum of evidencing value. SEDA Special, 34.

Bamber, V. \& Anderson, S. (2012) Evaluating learning and teaching: institutional needs and individual practices. International Journal for Academic Development, 17(1), 5-18.

Bamber, V. \& Trowler, P. (2005). Compulsory Higher Education Teacher Training: Joined-up policies, institutional architectures and enhancement cultures. International Journal for Academic Development, 10(2), 79-93.

Baume, D. (2008). A toolkit for evaluating educational development ventures. SEDA 9.4.

Biggs, J. (2003) Aligning teaching and assessing to course objectives. Teaching and Learning in Higher Education: New Trends and Innovations, 2, 13-17.

Bostock, S. J. (1998). Constructivism in mass higher education: a case study. British Journal of Educational Technology, 29, 225-240.

Bryman, A. \& Burgess, R. G. (Eds.). (1994). Analyzing qualitative data. London: Routledge.

Chalmers D. \& Thompson K. (2008). Snapshot of teaching and Learning Practice in Australian. Universities. Carrick Institute report on behalf of Australian Learning and Teaching Council.

Cohen, L., Manion, L \& Morrison, K. (2011) Research Methods in Education. $7^{\text {th }}$ Ed. London: Routledge

Department for Education and Skills. (2011). National Strategy for Higher Education to 2030. Dublin: Department of Education and Skills.

Entwistle, N. (2009). Teaching for Understanding at University. London: Palgrave Macmillan.

Fink, L. D. (2013). The Current Status of Faculty Development Internationally. International Journal for the Scholarship of Teaching and Learning, 7(2), http://w3.georgiasouthern.edu/ijsotl/v7n2.html.

Fleming, A. (2012). Developmental evaluation and the "double loop": adding value to the evaluation of complex change. SEDA Special 33.

Gibbs, G. and Coffey, M. (2004) The impact of training of university teachers on their teaching skills, their approach to teaching, and the approach to learning of their students. Active Learning in Higher Education, 5(1), 87-100.

Gosling, D. (2009). Educational development in the UK: a complex and contradictory reality. International Journal for Academic Development, 14(1), 5-18.

Guardian Professional - Higher Education Network. (2013). Stick or twist: the postdoctoral dilemma. Last accessed $15^{\text {th }}$ March 2014 at http://www.theguardian.com/higher-educationnetwork/blog/2013/jun/21/postfoc-dilemma-stick-or-twist

Hanbury, A., Prosser, M. \& Rickinson, M. (2008). The differential impact of UK accredited teaching development programmes on academics' approaches to teaching. Studies in Higher Education, 33(4), 469-483.

Harvey, J., Donnelly, R., McAvinia, C. (2013). Engaging lecturers as students: building sustainable

professional development. 6th Annual Learning Innovation Conference: Sustainable Models of

Student Engagement - Rhetoric or Achievable? Aisling Hotel Dublin, 17 October 2013.

Higher Education Authority (HEA). (2012). A Proposed Reconfiguration of the Irish System of Higher Education. Report of the International Expert Panel for the Higher Education Authority of Ireland. http://9thlevel.ie/wp-content/uploads/International Panel Report.pdf

Jordan, A., Carlile, O., \& Stack, A. (2008). Approaches to Learning: a Guide for Teachers. Maidenhead: Open University Press.

Kahn, P., Young, R., Grace, S., Pilkington, R., Rush, L., Tomkinson, B., Willis, T. (2006). The role and effectiveness of reflective practices in programmes for new academic staff: a grounded practitioner review of research literature. York: Higher Education Academy. 
Kandlbinder, P. \& Peseta, T. (2009). Key concepts in postgraduate certificates in higher education teaching and learning in Australasia and the United Kingdom. International Journal for Academic Development, 14(1), 19-31.

Knight, P., Tait, J., Yorke, M. (2006) The professional learning of teachers in higher education. Studies in Higher Education. 31 (3), 319-339.

Laurillard, D. (2001). Rethinking University Teaching: a conversational framework for the use of educational technology. London: Routledge.

Lucas, L. (2006). The Research Game in Academic Life, London, Palgrave.

Lueddeke, G.R. (2003). Professionalising Teaching Practice in Higher Education: a study of disciplinary variation and 'teaching scholarship'. Studies in Higher Education, 28(2), 213228.

McAvinia, C., Harvey, J., Donnelly, R., McDonnell, C., Hanratty, O. (2014) What has been the impact of accredited professional development for people teaching in higher education? UK Higher Education Academy 10th Annual Conference, Aston University, Birmingham, UK, 2nd-3rd July 2014.

NCIHE (National Committee of Inquiry into Higher Education). (1997). Higher Education in the Learning Society. Norwich: Crown Copyright.

O'Connell, T. \& Dyment, J. (2006). Reflections on using journals in higher education: a focus group discussion with faculty. Assessment \& Evaluation in Higher Education, 31(6), 671-691.

Parsons, D., Hill, I., Holland, J., \& Wills, D. (2012). Impact of teaching development programmes in higher education. York: Higher Education Academy.

Pickering, A. (2006). Learning about university teaching: reflections on a research study investigating influences for change. Teaching in Higher Education, 11(3), 319-335.

Prosser, M., Rickinson, M., Bence, V., Hanbury, A., \& Kulej, M. (2006). Formative evaluation of accredited programmes. Location, Higher Education Academy.

Rowland, S. (2002). Overcoming Fragmentation in Professional Life: The Challenge for Academic Development. Higher Education Quarterly, 56(1), 52-64.

Stake, R.E. (Ed.) (2004) Standards-based and responsive evaluation. Thousand Oaks, CA: Sage Publications.

Stefani, L. (Ed.) (2011) Evaluating the Effectives of Academic Development: Principles and Practice. Abingdon: Routledge

Stes, A., Clement, M., \& Van Petegem, P. (2007). The Effectiveness of a Faculty Training Programme: Long-term and institutional impact. International Journal for Academic Development, 12(2), 99-109.

THE (2014) World Rankings 2014, accessed $15^{\text {th }}$ March 2014 from http://www.timeshighereducation.co.uk/world-university-rankings/

Trigwell, K., Caballero Rodrigues, K., \& Han, F. (2012). Assessing the impact of a university teaching development programme. Assessment \& Evaluation in Higher Education, 37(4), 499-511. 


\section{ADDITIONAL READING SECTION}

Bamber, V., Walsh, L., Juwah, C. \& Ross, D. (2006) New lecturer development programmes: a case study of Scottish higher education institutions. Teacher Development 10 (2), 207-231

Bamber, V. \& Anderson, S. (2012) Evaluating learning and teaching: institutional needs and individual practices. International Journal for Academic Development. 17 (1), 5-18

Donnelly, R. (2006) Exploring lecturers' self-perception of change in teaching practice. Teaching in Higher Education. 11(2), 203-217

Fitzmaurice, M. (2013). Constructing professional identity as a new academic: a moral endeavour, Studies in Higher Education. 38(4), 613-622.

Gibbs, G. (2010) Dimensions of Quality. York: Higher Education Academy.

Gibbs, G. (2012) Implications of Dimensions of quality in a market environment. York: Higher Education Academy.

Gosling, D. \& Hannan, A. (2007). Responses to a policy initiative: the case of Centres for Excellence in Teaching and Learning. Studies in Higher Education, 32(5), 633-646.

Knight, P. (2002) A systemic approach to professional development: learning as practice. Teaching and Teacher Education. 18 (3), 229-241

Knight, P. (2006) Quality Enhancement and Educational Professional Development. Quality in Higher Education. 12 (1), 29-40

Kreber, C. \& Brook, (2001) Impact evaluation of educational development programmes. International Journal of Academic Development. 6(2) 96-108

MacCormack, C., \& Kelly, P. (2012). How Do We Know It Works? Developing and Evaluating a Professional Development Program for Part-Time Teachers. In F. Beaton \& A. Gilbert (Eds.), Developing Effective Part-Time Teachers in Contemporary Universities: New Approaches to Professional Development. London: SEDA Routledge

Nasr, A., Gillet, M., \& Booth E. (1996) Lecturers' teaching qualifications and their teaching performance. Research and Development in Higher Education, 18, 576-581.

Nicholls, G. (2005) New lecturers' constructions of learning, teaching and research in higher education, Studies in Higher Education, 30 (5), 611-625

Prebble, T., Hargraves, H., Leach, L., Naidoo, K., Suddaby, G., \& Zepke, N. (2004) Impact of Student Support Services and Academic Development Programmes on Student Outcomes in Undergraduate Tertiary Study: A Synthesis of the Research. Report to the Ministry of Education, New Zealand

Prince, M.J., Felder, R.M., \& Brent, R. (2007). Does faculty research improve undergraduate teaching? An analysis of existing and potential synergies. Journal of Engineering Education, 96(4), 283-294.

Rodgers, R., Christie, J., \& Wideman, M. (2014).The Effects of a Required Faculty Development Program on Novice Faculty Self-Efficacy and Teaching. Toronto: Higher Education Quality Council of Ontario

Rust, C. (2000). Do Initial Training Courses Have an Impact on University Teaching? The Evidence from Two Evaluative Studies of One Course. Innovations in Education and Training International 37(3), 254-262.

Rust, C. (2006). The impact of educational development workshops on teachers' practice. International Journal for Academic Development, 3(1), 72-80.

Sharpe, R. (2004) How do professional learn and develop? Implications for staff and educational developers. Chapter 8 in 'Baume, D. and Kahn, P. (eds.) (2004) Enhancing Staff and Educational Development. Abingdon: RoutledgeFalmer

Smith, J. (2005). From flowers to palms: 40 years of policy for online learning. Association for Learning Technology Journal (ALT-J), 13(2), 93-108.

Stefani, L. \& Elton, L. (2002) Continuing Professional Development of Academic Teachers through Self-initiated Learning, Assessment \& Evaluation in Higher Education, 27: 2, 117 - 129

Stes, A., Clement, M. \& Van Petegem, P. (2007) The Effectiveness of a Faculty Training Programme: Long-term and institutional impact. International Journal of Academic Development. 12 (2), 99-109 


\section{KEY TERMS \& DEFINITIONS (SUBHEAD 1 STYLE)}

(Please refer to author checklist to see if this applies to your submission)

Note - we were unsure if this applied to our submission

\footnotetext{
${ }^{\mathrm{i}}$ Institutes of Technology are tertiary level institutions in Ireland offering awards from apprentice through to doctoral levels, and traditionally having a closer relationship with applied practice and industry than universities.
} 